\title{
The Effects of Rapid Body Mass Loss on Body Composition and Athletic Performance in Combat Sports Athletes
}

\section{Hakan Yarar*, Anil Aliyazicioğlu, Yahya Eylenoğlu, Ridvan Enes Aydin, Erdi Akar, Recep Gürkan Yildirim}

Department of Sport Sciences, Bolu Abant Izzet Baysal University, Bolu, Turkey

Study Area: Bolu, Turkey

Coordinates: $40^{\circ} 40^{\prime} 45^{\prime \prime} \mathrm{N} ; 31^{\circ} 33^{\prime} 30^{\prime \prime} \mathrm{E}$

Key words: Dehydration; Dynamic balance; Reaction time; Strength.

This study was approved by the Clinical Research Ethics Committee of Abant Izzet Baysal University (Decision no:2018/230).

Introduction:

Weight management is an important issue for all weight categories of sports. Athletes are classified according to their body mass before the competition in these sports. They are participating in competitions many times a year. A lot of them lose body mass before a competition to qualify to participate. They usually reduce 2 to $10 \%$ of their body weight before every competition, mostly in the $2-3$ days before weigh-in (Artioli et al., 2016). To achieve body mass reduction athletes use a variety of weight loss methods such as reduce food and fluid consumption, vomiting to consumed foods, use diuretics pills, intensive exercise, and staying in the sauna for a long time (Largan-evans et al., 2011). Reports from combat sports (wrestling, karate, judo, and taekwondo) indicate that the use of these methods is highly prevalent among athletes (Gann et al., 2015; Artioli et al., 2010; Brito et al., 2012). However, many athletes reduce body mass in a short time before the matches to gain an advantage by competing against weaker opponents. This results in athletes risking both their health and athletic performance (Wilmore \& Costill, 2004). The health concerns of rapid body mass loss in combat sports date back to the 1930s. (Kenny, 1930). Due to the adverse effects of rapid body mass loss, in 1996, three months before the

\section{Abstract}

Sixteen healthy, active male combat sports athletes participate as a volunteer for this study. Athletes were lost minimum $3 \%$ of their body weight within 24 hours. During this period, body weight (BW), urine specific gravity (USG), body composition (total body water (TBW), muscle mass (MM), body fat mass (BF \%), visual reaction time (VRT) and auditory reaction time (ART), dynamic balance (DB), as well as handgrip strength (HS) and back extension strength (BES) were estimated. Measurements were taken in three different time (pre-test (baseline), post-test and during competition phase). No statistical significant difference in $\mathrm{DB}$, reaction time, $\mathrm{HS}$ and $\mathrm{BF} \%$ were evidenced. On the other hand statistically significant decrease was seen in BES, TBW and MM. Moreover significant increase was found in USG. The results of this study revealed that $3 \%$ body weight loss within 24 hours had negative effects on physical performance especially back extension strength. It was also observed that there were important changes in bodycomposition.

Atlanta Olympic Games, Chung Se-hoon (22 years old), in judo, was found dead in a sauna. In 1997, three wrestlers died due to hyperthermia and dehydration (Centers for Disease Control and Prevention, 1997). Equally, most studies have indicated that rapid body mass loss decreases both aerobic and anaerobic performance (Franchini et al., 2012) and muscle endurance (Timpmann et al., 2008).

As we know weight management is an inevitable fact for all weight classification sports. However, athletes' weight control practices must not adversely affect both performance and health. For this reason, body mass loss should bewell examined in all aspects.

There has been no study recently in the literature which examined specifically the effect of rapid body mass loss on dynamic balance performance as well as body composition measurement under real competition conditions. Therefore, the purpose of this study was to investigate the impact of rapid body mass loss on dynamic balance, handgrip, and back extension strength, visual and auditory reaction time. Furthermore, body fat percentage, total body water, muscle mass, and urine specific gravity were examined.

Materials and Methods:

16 healthy active male combat sports athletes from 6 
different sports (wrestling, karate, judo, boxing, kickboxing, and taekwondo) branches $[(\operatorname{mean} \pm \mathrm{SD})$ age: 21.94 \pm 2.11 years; experience: $8.31 \pm 3.09$ year; weight: $174.25 \pm 5.94 \mathrm{~cm}$; body mass: $74.16 \pm 11.78 \mathrm{~kg}$; body fat \%: $11.28 \pm 4.58$ ] who previously lost weight for competitions participated as a volunteer in this study. All participants were informed about the aim of the study, methods, contributions, and possible risks. After that, we completed a medical history form and signed informed consent for each participant.

Athletes were asked to lose a minimum of $3 \%$ of their body weight within 24 hours. Athletes have applied training, sauna, and food restriction for weight loss. Two weeks before the beginning of the study, athletes were familiarized with all performance tests to avoid the learning effect during the investigation. At this stage, each athlete had repeated the dynamic balance, reaction time, handgrip, and back extension strength test. 24 hours before the test, athletes were asked to refrain from consuming performance-enhancing beverages, diüretic pills, and heavy physical activity. On the first day of the study, anthropometric and body composition measurement, urine specific gravity, dynamic balance, reaction time, handgrip strength, and back extension strength were performed for evaluation of baseline values. Following baseline measurement, the weight ratio that the athletes should lose was calculated and reported to them. After that athletes started $3 \%$ of their body weight within 24 hours. At the end of the 24 hours, weight loss finished and post-test measurements were performed. After the pretests, a normal breakfast and 2 hours of rest were given to the athletes. After this period was completed, competition time measurements were made. All measurements are imitated (weight loss, weigh-in, breakfast, competition phase) in combat sports per competition rules. The experimental design of the study is shown in Table I.

\begin{tabular}{|c|c|c|c|c|}
\hline Pre-Test (Baseline) & $\begin{array}{l}\text { Weight loss protocol } \\
\text { (24 hour) }\end{array}$ & Post- Test & & $\begin{array}{l}\text { Competition phase } \\
\text { (24 After Post-Test) }\end{array}$ \\
\hline $\begin{array}{l}* \text { Urin specific gravity } \\
\text { Body, composition } \\
\text { Reaction time } \\
\text { Dynamic balance } \\
\text { Dyood grip strength } \\
\text { \& Back extension } \\
\text { strength }\end{array}$ & $\begin{array}{l}* \text { Weight loss training } \\
\text { Sauna (2o minute) } \\
\text { * Food restriction } \\
\text { - Fluid restriction }\end{array}$ & $\begin{array}{l}* \text { Urine specific gravity } \\
* \text { Body composition } \\
* \text { Reaction time } \\
* \text { Dynanmic balance } \\
* \text { Hand grip strength } \\
* \text { Back extension } \\
\text { strength }\end{array}$ & $*$ Breakfast & $\begin{array}{l}\text { * Urine specific gravity } \\
\text { *ody composition } \\
\text { * Reaction time } \\
\text { * Dynamic balance } \\
\text { * Hand grip strength } \\
\text { * Back extension } \\
\text { strength }\end{array}$ \\
\hline
\end{tabular}

Body fat percentage and fat-free mass measurements were performed by bioelectrical impedance analyzer (Tanita BC-418 MA; Tanita Corp., Japan) with barefoot. Height was measured to the nearest $\pm 0.1 \mathrm{~cm}$ via a stadiometer and body weight was measured to the nearest $\pm 0.1 \mathrm{~kg}$ via a manual scale (Seca 70o; Secagmbh \& co, Germany). During the measurement, all athletes were measured bywearing only light shorts.

For the assessment of urine specific gravity E-Line Hand Held Refractometer (B+S Code 44-891) with a scale ranging from 1.000 to 1.050 was used. After all measurements, it was cleaned with distilled water and prepared for the next measurement. The test was performed (before weight loss, after weight loss and after breakfast- competition phase) three times. Urine samples were collected in sterile containers and examined immediately. Moreover, all measurements were made by the same person to prevent possibleerror.

Dynamic balance performances were measured using a Biodex (Biodex Balance System, Inc, EN) device. Biodex has a moving platform that can tilt $20^{\circ}$ horizontally in all directions. Anterior-posterior, medial-lateral scores, and overall stability index were obtained from the Biodex. The overall stability index is an average tilt from the center of the platform. The higher numeric value of the overall stability index indicates worse balance performance and the lower overall stability index indicates better balance performance. Resistance levels of the platform range from 1 (least stable) to 12 (most stable). In our study 3 resistance level was applied (Costa et al., 2009). During the dynamic balance test without shoes and set foot in a comfortable position and foot position was recorded. Each participant performed a dynamic balance test in a recorded position. Participants performed 3 trials and each trial lasted the 20 . There were 10 resting between trials.

For the assessment of handgrip strength, Takei T.K.K. 5101 Grip dynamometer (Takei Scientific Instruments Co. Ltd, Tokyo, Japan) was used. During the measurements, dynamometers were calibrated and adjusted according to the hands and fingers of each participant. The measurements were repeated three times with the dominant hand and the best score was recorded (Tamer, 2000).

Takei brand TKK 5402 model (Back-D, Takei Scientific Instruments Co. Ltd., Tokyo, Japan) dynamometer was used for the measurement of back-leg strength. The participants stood on the platform with the knees fully extended and the trunk flexed about $30^{\circ}$ forward. The hand bar was positioned across the thighs, and thereafter the participants pulled it straight upward using the back muscle. Three trials were allowed with a 1-minute rest between the trials and the best score was recorded in kilogram-force.

For the assessment of visual and audial reaction time, Newtest 1000 reaction timer was used with the dominant hand. The subjects showed a response to the stimulus immediately. The subjects were tested three times and the bestvaluewas used.

Firstly mean and standard deviations (SD) were calculated for all measurements. Then, changes in all other times according to basal value were calculated respectively. Repeated measures of ANOVA were used for the determination of the difference between consecutive measurements pre-test (baseline), post-test, and competition phase. Bonferroni tests were defined as a post hoc test for pairwise comparison between pre-test 
(baseline), post-test, and competition phase measurements. The significance level was accepted as $\mathrm{p}=0.05$ and all statistical analyses were performed on SPSS version 2o.o.

\section{Results:}

The changes of BW, TBW, BFP, MM and USG at pre-test, post-test, competition phase are presented in Table-2.

Table-2: Body composition and urine specific gravity changes during weight loss.Data are means $( \pm$ SD and $\Delta \%)$

\begin{tabular}{llll}
\hline Variables & $\begin{array}{l}\text { Pre-test (Base) } \\
X \pm \mathrm{SD}\end{array}$ & $\begin{array}{l}\text { Post-test } \\
X \pm \mathrm{SD}\end{array}$ & $\begin{array}{l}\text { Competition phase } \\
X \pm \mathrm{SD}\end{array}$ \\
\hline $\mathrm{BW}(\mathrm{kg}) \Delta \%$ & $74.16 \pm 11.78$ & $71.47 \pm 11.47^{*}-3.6 \%$ & $72.57 \pm 11.50^{*}-2.1 \%$ \\
$\mathrm{TBW}(\mathrm{kg}) \Delta \%$ & $46.91 \pm 5.69$ & $45.12 \pm 6.00^{*}-3.8 \%$ & $46.14 \pm 5.83^{*}-1.6 \%$ \\
$\mathrm{BFP}(\%) \Delta \%$ & $8.90 \pm 4.81$ & $8.91 \pm 4.10$ & $8.33 \pm 4.51-6.40 \%$ \\
$\mathrm{MM}(\mathrm{kg}) \Delta \%$ & $61.13 \pm 7.41$ & $58.92 \pm 7.79^{*} 3.6 \%$ & $60.05 \pm 7.61^{*} 1.7 \%$ \\
USG $(\mathrm{gr} / \mathrm{ml})$ & $1021.94 \pm 6.86$ & $1033.44 \pm 3.22^{*}+1.17 \%$ & $1033.06 \pm 2.69^{*}+1.17 \%$ \\
\hline
\end{tabular}

Abbreviations: BW: Body Weight, TBW: Total Body Water, BFP: Body Fat Percentage, MM: Muscle Mass, USG: Urine Specific Gravity $\Delta \%$ percent change from the baseline. *Significant different than baseline.
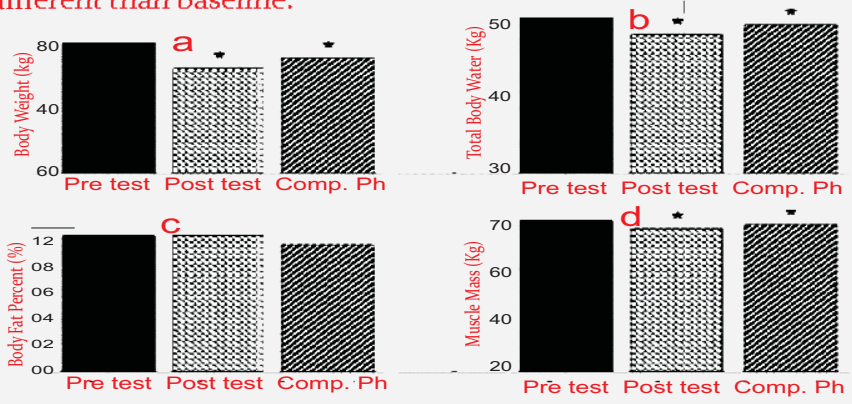

1040
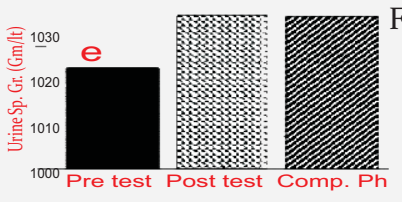

Figure-1: A: Body Weight, B: Total Body Water C: Body Fat D: Muscle Mass, E: Urine Specific Gravity

Table-3: Reaction time, strength and balance performance measurement of participants. Data are means $( \pm$ SD and $\Delta \%)$

\begin{tabular}{|c|c|c|c|}
\hline Variables & $\begin{array}{l}\text { Pre-test (Base) } \\
X \pm \text { SD }\end{array}$ & $\begin{array}{l}\text { Post-test } \\
X \pm \mathrm{SD}\end{array}$ & $\begin{array}{l}\text { Competition phase } \\
X \pm \text { SD }\end{array}$ \\
\hline VRT (sec) $\Delta \%$ & $0.228 \pm 0.33$ & $0.217 \pm 0,22-4.82 \%$ & $0.230 \pm 0.42+0.87 \%$ \\
\hline ART (sec) $\Delta \%$ & $0.166 \pm 0.23$ & $0.177 \pm 0.54+6.62 \%$ & $0.166 \pm 0.25$ \\
\hline $\mathrm{HS}(\mathrm{kg}) \Delta \%$ & $52.11 \pm 6.79$ & $52.89 \pm 6.87+1.49$ & $52.58 \pm 7.17+0.90 \%$ \\
\hline $\mathrm{BES}(\mathrm{kg}) \Delta \%$ & $167.53 \pm 15.58$ & $165.30 \pm 25.49-1.33 \%$ & $150.40 \pm 21.69^{*}-10.22 \%$ \\
\hline DB (overall) $\Delta \%$ & $\% \quad 1.063 \pm 0.43$ & $1.081 \pm 0.65+1.69 \%$ & $1.050 \pm 0.78-1.22 \%$ \\
\hline
\end{tabular}

Abbreviations: VRT: Visual Reaction Time, ART: Auditory Reaction Time, HS: Handgrip Strength, BES: Back extension Strength, DB: Dynamic Balance (Overall Stability). $\Delta \%$ percent change from the baseline. *Significant different than baseline.

\section{Discussion:}

In this study, the effects of rapid weight loss on body composition, strength, dynamic balance, and reaction time were investigated in elite combat sports athletes. In this process, athletes reduced their body weight average of $3.6 \%$ within 24 hours (Figure $1 \mathrm{~A}$ ). The important findings obtained are as follows; TBW, MM, BES was decreased. At the same time, USG was increased due to rapid weight loss. On the other hand, there were no statistically significant differences in BF\%, HS, DB, VRT, and ART.

Statistically, a significant decrease was found between TBW values when compared with baseline, after weight loss and competition phase. This result was also confirmed in studies other authors by Ashtary-larky et al., (2017); Moghaddami et al., (2016); Reljic et al., (2013); Coufalová et al., (2013); Sagayama et al., (2014); Durkalec-Michalski et al., (2014); Kondo et al., (2018) also found a significant decrease in TBW after body weight loss. The reason for the decline in TBW can be attributed to athlete's weight loss; restricted fluid consumption, training intensively with the raincoat, and the use of a sauna.

There is no statistically significant difference in BFP values. Similarly, Rashidlamir et al., (2009) and Gulati et al., (2006) found the same result as our study. In general, body fluids decrease in rapid weight loss performed in a short time and there is no significant change in fat ratios. A longer time is needed for a significant change in the fat ratio.

Statistically, a significant decrease was observed in MM values. Kukidome et al., (2008) evaluated the body composition changes in rapid weight loss with magnetic resonance (MR) and they found that total muscle area was significantly less on the day of the weigh-in and competition. At the same time Sagayama et al., (2014); Kondo et al., (2018), and Coufalová et al., (2013); found that fat-free mass decreased after the weight-loss period. The muscles are mostly composed of water. Loss of intense body water and severe food restriction due to rapid weight loss causes muscular losses.

When USG values were examined, a statistically significant increase was found between the measurement times. This increase was seen after the weight loss and competition phase. Likewise, Périard et al., (2012) reported a statistically significant increase in USG after 3.2\% acute weight loss. At the same time Rivera-Brown \& De FélixDávila, (2012) reported a significant increase in USG as a result of bodyweight loss during the exercise. Rodrigues et al., (2014) found that there was a statistically significant increase in USG after bodyweight reduction in exercise in a hot environment. Evetovich et al., (2002) reported that there was a significant increase in USG after $2.9 \%$ rapid weight loss in their study. When the present study and the studies mentioned above were examined, it is correct to say that the athletes of weight category sports were dehydrated after weight loss. It is known that for rapid weight loss the athletes use many different weight loss methods such as nutrient restriction, intensive exercise, and sauna. Due to these applications, severe fluid losses are experienced in the body, increasing USG.

In the present study, there are no statistically significant changes in VRT and ART in rapid weight loss (Figure $2 \mathrm{~A}, \mathrm{~B}$ ). Similarly, Wilson et al., (2014) in their study found no significant difference in reaction times. Furthermore, food and fluid restriction due to Ramadan fasting did not 
influence reaction times values in elite karate athletes (Zarrouk et al., 2016), though this practice differs greatly from rapid weight loss strategies in weight category sports that likely include dehydration and exercise in rubber or plastic suits. Muscle activation is one of the most important factors affecting reaction time. Sodium and potassium are the electrolytes responsible for muscle activation. When the studies were examined, it was found that there were no decrease in both muscle activation (Hayers \& Morse, 2010) and minerals (Reljic et al., 2013; Fogelholm et al., 1993; Costill et al., 1976) responsible for muscle activation after rapid weight loss. It can be said that there is no difference in reaction time due to the reasons mentioned above.

There is no statistically significant difference when the HS performances were examined. Similarly, Serfass et al., (1984) stated that $5 \%$ weight loss in 3 days had no effect on handgrip strength. Gutierrez et al., (2003) stated that there was no change in handgrip strength after rapid weight loss due to sauna. Filaire et al., (2001) reported that there was no significant change in the right-hand grip strength of the body by a $4.9 \%$ decrease in body weight as a result of 7 -day food restriction. At the same time Gulati et al., (2006) and Marttinen et al., (2011) found that a non-significant decline in handgrip strength was observed after weight reduction. In high-intensity exercises, energy is provided from the ATP-CP system. There is very little stored ATP in muscle cells. ATP molecule is used continuously at different rates. Therefore, it should be replaced immediately when used (Sönmez, 2002). Houston et al., (1981) stated that there was no change in muscle ATP and CP concentration after $8 \%$ weight loss through 4-day food and fluid restriction. For this reason, it is thought that there is no change in the handgrip strength due to the absence of change in muscle ATP-CP concentration.

It was established that there was a statistically significant decrease in BES (Figure 2D). The decrease was seen between the basal, after weight loss, and competition phase values. Similarly, Kraemer et al., (2001) and Wilson et al., (2014), found a statistically significant decrease in upper and lower extremity forces after weight loss. It is seen that combat sports athletes use many different weight loss methods such as nutrient and fluid restriction, intensive training, and sauna use. These methods cause heavy fluid loss in the body and rapid depletion of carbohydrate storage. Sudden reduction in carbohydrate stores increases cortisol release in the body (Kraemer et al., 2001). Cortisol begins to produce glucose from proteins and fats that are noncarbohydrate sources of energy (Gluconeogenesis). Thus, the blood glucose level is tried to be kept in balance (Günay et al., 2010). Accordingly, muscle destruction occurs resulting in a decrease in muscle tissue and strength.

Despite the importance of dynamic balance for athletic performance in body weight classification sports, almost no studies in the literature have investigated the effects of rapid weight loss on DB performance. In this study, there is no statistically significant difference in DB performance after weight loss. Similarly, Cullen et al., (2015) reported that there was no statistically significant difference in DB performance after $4 \%$ body weight loss. It is thought that a potential habit may be possible among the combat athletes on the loss of body weight in these amounts and the effects of dehydration levels associated therewith. In this respect, it can be said that there is no significant change in balance performance in low body weight loss. Bodyweight loss of more than $4 \%$ can be examined in future studies with the effects of weight loss on balance performance.

\section{References:}

Artioli, G.G., Gualano, B., Franchini, E., Scagliusi, F.B., Takesian, M., Fuchs, M. \& Antonio-Herbert-Lancha, J.R. (2010): Prevalence, magnitude, and methods of rapid weight loss among judo competitors. Med. Sci. Sports Exer., 42(3):436442.

Artioli, G.G., Saunders, B., Iglesias, R.T. \& Franchini, E. (2016): It is time to ban rapid weight loss from combat sports. Sports Med., 46(11):1579-1584.

Ashtary-Larky, D., Ghanavati, M., Lamuchi-Deli, N., Payami, S.A., Alavi-Rad, S., Boustaninejad, M., Afrisham, R., Abbasnezhad, A. \& Alipour, M. (2017): Rapid weight loss vs. slow weight loss: which is more effective on body composition and metabolic risk factors $\Delta$ Int. J. Endocrinol. Metab., 15(3):13249.

Brito, C.J., Roas, A.F.C.M., Brito, I.S.S., Marins, J.C.B., Córdova, C. \& Franchini, E. (2012): Methods of body-mass reduction by combat sport athletes. Int. J. Sport Nutr. Exer. Metab., 22(2):89-97.

Centers for Disease Control and Prevention (CDC) (1998): Hyperthermia and dehydration-related deaths associated with intentional rapid weight loss in three collegiate wrestlers--North Carolina, Wisconsin, and Michigan, November-December 1997. $M M W R, 47(6): 105$.

Costa, P.B., Graves, B.S., Whitehurst, M. \& Jacobs, P.L. (2009): The acute effects of different durations of static stretching on dynamic balance performance. L. Streng. Cond. Res., 23(1):141-147.

Costill, D.L., Cote, R. \& Fink, W. (1976): Muscle water and electrolytes following varied levels of dehydration in man. $L$. Appl. Physiol., 40(1):6-11.

Coufalova, K., Prokesova, E., Maly, T. \& Heller, J. (2013): Body weight reduction in combat sports. Arch. of Budo, 9(4):267272.

Cullen, S., Dolan, E., Brien, K. O., McGoldrick, A. \& Warrington, G. (2015): Lack of effect of typical rapid-weight-loss practices on balance and anaerobic performance in apprentice jockeys. Int. J. Sports Physiol. Performance, 10(8):972-977.

Durkalec-Michalski, K., Goscianska, I., Jeszka, J. \& Podgórski, T. (2014): The effect of conventional methods of body weight reduction on overall sense of well-being, body composition, and anaerobic capa city of athletes practicing selected combat sports. L. Combat Sports Martial Arts, 2(2):89-95.

Evetovich, T.K., Boyd, J.C., Drake, S.M., Eschbach, L.C., Magal, M., 
GENERAL ARTICLE

Soukup, J.T., Webster, J.M., Whitehead, M.T. \& Weir, J.P. (2002): Effect of moderate dehydration on torque, electromyography, and mechanomyography. Muscle Nerve, 26(2):225-231.

Filaire, E., Maso, F., Degoutte, F., Jouanel, P. \& Lac, G. (2001): Food restriction, performance, psychological state and lipid values in judoathletes. Int. J. Sports med., 22(o6):454-459.

Fogelholm, G.M., Koskinen, R., Laakso, J., Rankinen, T. \& Ruokonen, I. (1993): Gradual and rapid weight loss: effects on nutrition and performance in male athletes. $\underline{\text { Med. Sci. Sports }}$ Exer., 25(3):371-377.

Franchini, E., Brito, C.J. \& Artioli, G.G. (2012): Weight loss in combat sports: physiological, psychological and performance effects. J. Int. Society Sports Nutr., 9(1):52.

Gann, J.J., Tinsley, G.M. \& La Bounty, P.M. (2015): Weight cycling: prevalence, strategies, and effects on combat athletes. Strength Condition. J., 37(5):105-111.

Gulati, A., Wasuja, M. \& Kumari, N. (2006): Effect of weight reduction on selected physiological parameters in male junior national boxing campers. L. Exer. Sci. Physiother., 2(35).

Günay, M., Tamer, K. \& Cicioglu, I. (2010): Sport Physioloğy and Performance Measurement [Spor Fizyolojisi ve performansölçümü] Ankara.

Gutierrez, A., Mesa, J.L.M., Ruiz, J.R., Chirosa, L.J. \& Castillo, M.J. (2003): Sauna-induced rapid weight loss decreases explosive power in women but not in men. Int. J. Sports Med., 24(07):518-522.

Hayes, L.D. \& Morse, C.I. (2010): The effects of progressive dehydration on strength and power: is there a dose response $\Delta$ Eu.J.Appl. Physiol., 108(4):701-707.

Houston, M.E., Marrin, D.A., Green, H.J. \& Thomson, J.A. (1981): The effect of rapid weight loss on physiological functions in wrestlers. Physician Sports Med., 9(11):73-78.

Kenny, H.E. (1930): The problem of making weight for wrestling meets. J. Health Phys. Edu., 1:24-25.

Kondo, E., Sagayama, H., Yamada, Y., Shiose, K., Osawa, T., Motonaga, K., Ouchi, S., Kamei, A., Nakajima, K., Higaki, Y., Tanaka, H., Takahashi, H. \& Okamura, K. (2018): Energy deficit required for rapid weight loss in elite collegiate wrestlers. Nutr., 10(5):536.

Kraemer, W.J., Fry, A.C., Rubin, M.R., Triplett-McBride, T., Gordon, S. E., Koziris, L.P. \& Fleck, S.J. (2001): Physiological and performance responses to tournament wrestling. $\underline{\text { Med. }}$ Sci. Sports Exer., 33(8):1367-1378.

Kukidome, T., Shirai, K., Kubo, J., Matsushima, Y., Yanagisawa, O., Homma, T. \& Aizawa, K. (2008): MRI evaluation of body composition changes in wrestlers undergoing rapid weight loss. Br. J. Sports Med., 42(10):814-818.

Langan-Evans, C., Close, G.L. \& Morton, J.P. (2011): Making weight in combat sports. Strength Cond. J., 33(6):25-39.

Marttinen, R.H., Judelson, D.A., Wiersma, L.D. \& Coburn, J.W. (2011): Effects of self-selected mass loss on performance and mood in collegiate wrestlers. J. Streng. Condi. Res., 25(4):10101015.
Ambient Science, 2020: Vol. 07(Sp1); 337-341 DOI:10.21276/ambi.2020.07.sp1.ga05

Moghaddami, A., Gerek, Z., Karimiasl, A. \& Nozohouri, H. (2016): The effect of acute dehydration and rehydration on biomechanical parameters of elite wrestling techniques. $L$. Sports Sci., 4:93-101.

Périard, J.D., Tammam, A.H. \& Thompson, M.W. (2012): Skeletal muscle strength and endurance are maintained during moderatedehydration. Int.J. Sports Med., 33(08):607-612.

Rashidlamir, A., Goodarzi, M. \& Ravasi, A. (2009): The comparison of acute and gradual weight loss methods in well-trained wrestlers. World J. Sport Sci., 2(4):236-240.

Reljic, D., Hässler, E., Jost, J. \& Friedmann-Bette, B. (2013): Rapid weight loss and the body fluid balance and hemoglobin mass of elite amateur boxers. J. Athletic Training, 48(1):109-117.

Rivera-Brown, A.M. \& De Félix-Dávila, R.A. (2012): Hydration status in adolescent judo athletes before and after training in the heat. Int.J. Sports Physiol. Perform., 7(1):39-46.

Rodrigues, R., Baroni, B.M., Pompermayer, M.G., de Oliveira Lupion, R., Geremia, J.M., Meyer, F. \& Vaz, M.A. (2014): Effects of acute dehydration on neuromuscular responses of exercised and nonexercised muscles after exercise in the heat. J. Strength \& Conditioning Res., 28(12):3531-3536.

Sagayama, H., Yoshimura, E., Yamada, Y., Ichikawa, M., Ebine, N., Higaki, Y. \& Tanaka, H. (2014): Effects of rapid weight loss and regain on body composition and energy expenditure. Appl. Physiol. Nutr. Metabolism, 39(1):21-27.

Serfass, R.C., Stull, G.A., Alexander, J.F. \& Ewing Jr, J.L. (1984): The effects of rapid weight loss and attempted rehydration on strength and endurance of the handgripping muscles in college wrestlers. Res. Quar. Exer. Sport, 55(1):46-52.

Sönmez, G.T. (2002): Eğzersiz ve spor fizyolojisi. Ankara Ata Ofset Matbaacilik, 23.

Tamer, K. (2000): Physical and physioloğical performance measurement and evaluation in sports. 2nd Edition. Pub. by: Bagirgan Publishing House, Ankara.

Timpmann, S., Ööpik, V., Pääsuke, M., Medijainen, L. \& Ereline, J. (2008): Acute effects of self-selected regimen of rapid body mass loss in combat sports athletes. J. Sports Sci. Med., $7(2): 210$.

Wilmore, J.H. \& Costill, D.L. (2004): Physioloğy of Sport and Exercise. 3 rd. Hong Kong. Human Kinetic.

Wilson, G., Hawken, M.B., Poole, I., Sparks, A., Bennett, S., Drust, B., Morton, J. \& Close, G.L. (2014): Rapid weight-loss impairs simulated riding performance and strength in jockeys: implications for making-weight. J. Sports Sci., 32(4):383-391.

Zarrouk, N., Hammouda, O., Latiri, I., Adala, H., Bouhlel, E., Rebai, H. \& Dogui, M. (2016): Ramadan fasting does not adversely affect neuromuscular performances and reaction times in trained karate athletes. J. Int. Society Sports Nutr., 13(1):18. 